\section{Swiss science set to stay international}

Curbs on immigration resulting from last month's Swiss referendum (see Nature $\mathbf{5 0 6}, 265 ; 2014$ ) have led to Switzerland's exclusion from the competition for European Research Council (ERC) grants. This is a devastating blow, given that the country has the highest share of international researchers on ERC grants. Thanks to the Swiss National Science Foundation (SNSF) stepping in to run a temporary parallel programme, however, Swiss science can remain international and competitive.

The SNSF has supported basic science through singleinvestigator grants for more than 60 years. The new temporary SNSF schemes will help researchers who are working in Switzerland or negotiating with Swiss institutions and who were planning to participate in the ERC competition. The schemes will have similar deadlines, procedures and success rates to the ERC's, and the evaluation panels will comprise distinguished scientists from Switzerland and abroad.

ERC grants represent a sort of 'Champions League' for researchers in Europe, and so it will not be easy to run a local programme of the same calibre. However, Switzerland will now be able to maintain its strong international track record: $49 \%$ of our professorial bodies are international, $33 \%$ of our researchers are abroad, and 28\% of our students are foreigners. Martin Vetterli SNSF, Bern, Switzerland. martin.vetterli@snf.ch

\section{Publish results from volunteer computing}

In your discussion of waning participation in volunteer computing projects (Nature 506, 16-17; 2014), you omit to mention the most important motivator of all - contribution

to scientific progress.

For instance, a review of completed projects on IBM's World Community Grid for biomedical research uncovers a lacklustre track record in scientific output (see go.nature. $\mathrm{com} / \mathrm{fkheej}$ ). Four out of 16 of these projects have yet to produce any publications, even though the earliest project was completed more than 5 years ago. Others have generated only non-peer-reviewed output, such as book chapters or conference proceedings. Of the peerreviewed publications, several focused solely on the technical aspect of distributed computing, with no analysis of the computed results.

To maintain the viability of volunteer computing projects, researchers should be reminded that public support and confidence are gained through professional and timely communication of results. Otherwise, online titles or badges amount to no more than virtual candy.

Herman Tse University of Hong Kong, Hong Kong.

htse@hku.hk

\section{Thwart fatal infant gut parasite}

Vaccination against

cryptosporidiosis, a devastating

disease for children in the developing world caused by a protozoan parasite, has met with limited success (P. Hotez Health Affairs 30, 1080-1087; 2011). A better way to prevent this and other enteric diseases in such settings is to address shortcomings in hygiene.

When funding is in short supply, more investment in basic research is not the only solution (see B. Striepen Nature 503, 189-191; 2013). Increasing efforts to extend interventions that are known to work already are more likely to bring immediate, tangible and costeffective benefits.
The most significant gains will be achieved through education and the design, deployment and uptake of suitable sanitation and potable-water systems within the affected communities.

Brendon King, Paul Monis Australian Water Quality Centre, Adelaide, Australia.

brendon.king@sawater.com.au

\section{Steering plans for neglected diseases}

Mary Moran criticizes plans by the World Health Organization (WHO) for tackling neglected diseases in the developing world (Nature 506, 267; 2014). Her arguments are misleading and trivialize global efforts to fix the research and development (R\&D) system that is failing to address the health needs of people in these countries.

After 10 years' effort by WHO member states, the WHO Consultative Expert Working Group on R\&D Financing and Coordination has proposed a framework to tackle these R\&D shortcomings. This aims to promote and coordinate needsdriven innovation, sustainable funding mechanisms and patient access to health technologies.

Moran contends that the current drug pipeline for neglected diseases is "successful". In the past ten years, however, only $4 \%$ of all new drugs and vaccines and $1 \%$ of all new chemical entities were for neglected diseases and none was suitable for the 17 neglected tropical diseases (B. Pedrique et al. Lancet Glob. Health 1, e371-e379; 2013). Increased funding and better coordination will help, but what is really needed is a greater global incentive for needsdriven $\mathrm{R} \& \mathrm{D}$.

To fulfil the working group's criteria, the WHO pilot projects need better coordination, optimization of research and accelerated delivery of health tools. This will be achieved only by strengthening capacity, testing innovative or pooled financing, developing an open-knowledge approach, and unlinking $\mathrm{R} \& \mathrm{D}$ costs from the end price of products.

Bernard Pécoul Drugs for

Neglected Diseases initiative,

Geneva, Switzerland.

bpecoul@dndi.org

Manica Balasegaram Médecins

Sans Frontières, Geneva,

Switzerland.

\section{Research problems in Portugal run deep}

As founders of the Portuguese National Association of Researchers in Science and Technology (ANICT), we believe that research problems in the country run deeper than just funding (see Nature 507, 306; 2014).

Evaluation procedures for recruitment, career progression and funding allocation are in need of fundamental reform. They must become more transparent and be based solely on merit.

Selection for nationally funded $\mathrm{PhD}$ and postdoc scholarships, for example, is beset by conflicting interests and insufficient transparency (see www.anict.pt). The recent cuts in scholarship numbers have exacerbated these factors.

Currently, merit has little influence on career stability or advancement. Many researchers, even team leaders with students and ongoing grants, are being driven to leave the country because of their non-renewable, short-term contracts.

Instead of bickering and passing the buck, Portugal's politicians need to agree on long-term plans to foster and retain the country's talented young researchers.

Nuno Cerca University of Minho, Braga, Portugal. nunocerca@ceb.uminho.pt João Lopes University of Lisbon, Portugal.

Miguel Jorge University of Strathclyde, Glasgow, UK. 